\title{
Identifying enablers and barriers to individually tailored prescribing: a survey of healthcare professionals in the UK
}

\author{
Joanne Reeve ${ }^{1 *}$ D, Nicky Britten ${ }^{2}$, Richard Byng ${ }^{3}$, Jo Fleming ${ }^{4}$, Janet Heaton ${ }^{5}$ and Janet Krska ${ }^{6}$
}

\begin{abstract}
Background: Many people now take multiple medications on a long-term basis to manage health conditions. Optimising the benefit of such polypharmacy requires tailoring of medicines use to the needs and circumstances of individuals. However, professionals report barriers to achieving this in practice. In this study, we examined health professionals' perceptions of enablers and barriers to delivering individually tailored prescribing.

Methods: Normalisation Process Theory (NPT) informed an on-line survey of health professionals' views of enablers and barriers to implementation of Individually Tailored Prescribing (ITP) of medicines. Links to the survey were sent out through known professional networks using a convenience/snowball sampling approach. Survey questions sought to identify perceptions of supports/barriers for ITP within the four domains of work described by NPT: sense making, engagement, action and monitoring. Analysis followed the framework approach developed in our previous work.

Results: Four hundred and nineteen responses were included in the final analysis (67.3\% female, 32.7\% male; $52.7 \%$ nurse prescribers, 19.8\% pharmacists and 21.8\% GPs). Almost half (44.9\%) were experienced practitioners (16+ years in practice); around one third reported already routinely offering ITP to their patients. GPs were the group least likely to recognise this as consistent usual practice. Findings revealed general support for the principles of ITP but significant variation and inconsistency in understanding and implementation in practice. Our findings reveal four key implications for practice: the need to raise understanding of ITP as a legitimate part of professional practice; to prioritise the work of ITP within the range of individual professional activity; to improve the consistency of training and support for interpretive practice; and to review the impact of formal and informal monitoring processes on practice.
\end{abstract}

Conclusion: The findings will inform the ongoing development of our new complex intervention (PRIME Prescribing) to support the individual tailoring of medicines needed to address problematic polypharmacy.

Keywords: Polypharmacy, Medicines optimisation, Individually tailored care

\section{Background}

Polypharmacy-the use of multiple medicines in one individual on a long-term basis-is now routine in clinical practice [1]. To optimise the potential benefit of polypharmacy on patient-centred outcomes, we must find ways to support compromise between the views of clinicians and patients when making decisions about medicines use $[1,2]$.

Growing numbers of patients take multiple medicines in order to optimise management of their (often multiple)

\footnotetext{
* Correspondence: Joanne.reeve@hyms.ac.uk

'Hull York Medical School, Hull University, Cottingham Road, HU67RX, Hull, England

Full list of author information is available at the end of the article
}

disease(s). Polypharmacy can improve patient outcomes $[1,3,4]$. However, long term medication use can also be problematic for patients - burdensome in multiple ways [2, 5-14]. Professional responses have seen the introduction of medicines optimisation strategies, aiming to make it easier for patients to take their medicines as prescribed. But non-concordance is common. For some patients, this is a passive process - the result of being overwhelmed by medication demands that they cannot meet. Others engage in an active resistance to medication use based on thoughtful evaluation of the pros and cons of medicines use [12]. Some people are able to negotiate these decisions with their health care practitioners to reflect the needs 
demands and priorities of their individual circumstances $[2,6]$; but this is by no means universal. Capacity to support individually tailored prescribing - what Denford has described as Mutually Agreed Tailoring (MAT) of medicines [2] - is essential to optimising the use of the medical intervention that is polypharmacy $[1,2]$.

Previous research has highlighted barriers to individualised (whole person) tailoring of general medical decisions within current managed health systems [15, 16]. These include a lack of resources, skills and training supporting delivery of personalised (generalist) decision making. Professionals describe wanting to deliver individually tailored care, but being unable to do so in practice.

Our team are developing a new model of practice (PRIME prescribing) to support the MAT of medicines use highlighted by Denford's work [2]. To refine our description of the core elements of our new complex intervention, we wanted to look specifically at current professional perceptions of delivering individually tailored prescribing. Our research question asked: what factors enable or limit health professionals in delivering individually tailored prescribed in every day practice? The results will be used to refine our PRIME prescribing model going in to feasibility testing.

\section{Method}

\section{Research design}

A cross-sectional mixed methods study using an on-line survey instrument informed by Normalisation Process Theory (NPT) [17]. The tool aimed to identify perceptions of enablers and barriers to the integration of individually tailored prescribing into routine medical practice in a convenience sample of health professionals.

\section{Sample}

We sought to contact health professionals (doctors, nurses, pharmacists) potentially dealing with problematic polypharmacy including those actively engaged in prescribing medicines, and those supporting patients who are taking multiple medicines. We used a snowball sampling approach to send invitations through known networks of professional contacts including newsletters to GPs, pharmacists and other primary health care professionals. Networks used included the Society for Academic Primary Care (SAPC), regional networks for the Royal College of GPs (RCGP), RCGP First Five network (recently qualified GPs), known Continuing Professional Development networks, the Prescribing and Research in Medicines Management group, the Royal Pharmaceutical Society, and Local Pharmacy Forums. The survey was publicised in the Pharmacy Research UK Newsletter. We also sent Twitter invitations targeting RCGP, SAPC, and known experts in the field; all links included an invitation to pass details on to individuals' own networks. Our aim was for maximum reach sampling rather than a statistically representative sample. To support internal consistency, we opted to use data only from UK professionals from the 3 main professional groups-doctors, nurse prescribers and pharmacists.

\section{Instrument development}

Was informed by Normalisation Process Theory (NPT) see Table 1 - with the tool being adapted by the research team from the NOMAD instrument [18], NPT toolkit [17], and a previous survey instrument used to examine barriers to generalist practice [15]. Questions examined whether participants recognised work within each of the four key domains described by NPT as needing to happen for the practice of individually tailored prescribing to become integrated into every day care. All responses were anonymous, however basic characteristics on type and location of professional practice together with years in practice were collected. The draft survey was road tested with a small sample of GPs and pharmacists to ensure it was useable. The full tool is shown in Additional file 1 and can be viewed at this link https:// www.surveymonkey.co.uk/r/7MDY8MF

Data collection: the survey tool (including an invitation, participant information sheet, consent recording and data collection) was loaded on to Survey Monkey. The survey was open for one month (January-February 2016). No personal identifiable information was collected.

\section{Analysis}

For each theme, our analysis sought to identify evidence of successful work supporting individual tailoring together with problem areas. For the quantitative data,

Table 1 Using normalisation process theory to assess individually tailored prescribing

Normalisation Process Theory predicts that for a new intervention to become integrated into usual practice, there needs to be continuous investment by all parties in four areas of work. These include

- Making Sense of the intervention: everyone must understand how the intervention is distinct from other ways of working and why it matters

- Engagement: individuals and collectively people must commit to do the work of the new practice

- Action: people must have the skills and resources to deliver the new way of working

- Monitoring: people must get feedback which reinforces and encourages this way of working

May and colleagues designed a 16 item questionnaire to support the critical examination of these areas of work in assessing implementation and integration of ways of working [17]. The tool has been updated into a more user friendly format in the NOMAD tool [18].

We have previously used the toolkit to examine the enablers and barriers to delivery of expert generalist practice (EGP) in the primary care setting [15]. In this study, we will use the same approach to examine individually tailored prescribing. 
descriptive statistical analysis (absolute numbers, percentages and crosstabs reports) was undertaken by JR with support from SPSS software to describe the characteristics of participants and to compare responses between professional groups and years of practice. Free text responses were analysed by JR and JF using a constant comparative approach [15] to identify enablers and barriers to work in each area. An a priori coding framework was used based on the NPT descriptors (see Table 1) but with researchers remaining alert for new themes emerging. Disagreement was addressed through discussion. Using a framework analysis approach used in our previous work in this area [15], findings were critically reviewed to distil key enablers and barriers to generalist practice in each of the four domains described by NPT [17]. We thus sought to describe key changes needed to support implementation of ITP in everyday practice.

\section{Results}

\section{Describing our sample}

Four hundred and forty-four professionals responded to the survey. To enhance the potential generalisability of our findings, we opted to exclude the small number of responses received from practitioners outside of the UK $(n=6)$, and those from outside the three main professional groups involved in prescribing within UK primary care practice - nurse prescribers, pharmacists or GPs ( $n$ $=25$ ). Our final sample thus consisted of 419 people: $52.7 \%$ of whom were nurse prescribers, $19.8 \%$ pharmacists and 21.8\% GPs (Table 2). There were more women than men in our sample - partly reflecting the strong nursing representation, as well as known gender bias in survey response [54]. We had responses from people at all career stages - early (17.7\%), middle (37.2\%) and later career $(44.9 \%)$ - with respondents tending to be more experienced practitioners. Almost one third of our sample felt they were already routinely offering ITP to their patients. GPs were the group least likely to recognise this as consistent usual practice. However, a further $53.2 \%$ of participants described offering ITP some of the time - including $80.4 \%$ of GP respondents.

Analysis of responses from this group are presented under the four NPT domains used in our survey design.

\section{Sense making}

NPT predicts that for ITP to become an integral part of everyday practice, it must be easy to describe, offer a distinct model of care that is different from other ways of working, with all stakeholders being clear about the aims of practice, expected tasks and value/importance of the work [17]. Analysis of quantitative and free text responses revealed four themes in this domain: that ITP is

Table 2 Summarising the professional experience and location of participants

\begin{tabular}{|c|c|c|c|c|}
\hline & Nurse prescriber & GP & Pharmacists & Total \\
\hline Total number (\% of sample) & $n=234(52.7 \%)$ & $n=97(21.8 \%)$ & $n=88(19.8 \%)$ & 419 (100\%) \\
\hline \multicolumn{5}{|l|}{ Gender } \\
\hline Male $(n, \%)$ & $31(13.2 \%)$ & $49(50.5 \%)$ & $54(61.3 \%)$ & $134(32.0 \%)$ \\
\hline Female $(n, \%)$ & $200(85.5 \%)$ & $48(29.5 \%)$ & $34(38.7 \%)$ & $282(67.3 \%)$ \\
\hline Missing data & $3(1.3 \%)$ & 0 & 0 & $3(0.7 \%)$ \\
\hline \multicolumn{5}{|l|}{ Career stage } \\
\hline Early career: $\leq 5$ years $(n, \%)$ & $58(24.8 \%)$ & $5(5.1 \%)$ & $11(12.5 \%)$ & $74(17.7 \%)$ \\
\hline Mid career: 6-15 years $(n, \%)$ & $76(32.4 \%)$ & $27(27.8 \%)$ & $53(60.2 \%)$ & $156(37.2 \%)$ \\
\hline Later career: $16+$ years $(n, \%)$ & 99 (42.3\%) & $65(67 \%)$ & $24(27.2 \%)$ & $188(44.9 \%)$ \\
\hline Missing data & $1(0.4 \%)$ & 0 & 0 & $1(0.2 \%)$ \\
\hline \multicolumn{5}{|l|}{ Location of practice } \\
\hline England $(n, \%)$ & & & & $400(95.5 \%)$ \\
\hline Scotland $(n, \%)$ & & & & $6(1.4 \%)$ \\
\hline Ireland $(n, \%)$ & & & & $4(0.9 \%)$ \\
\hline Wales $(n, \%)$ & & & & $9(2.1 \%)$ \\
\hline Missing data & & & & 0 \\
\hline \multicolumn{5}{|l|}{ Reporting currently providing ITP } \\
\hline Yes, always $(n, \%)$ & $96(41.0 \%)$ & $13(13.4 \%)$ & $12(13.6 \%)$ & $121(28.9 \%)$ \\
\hline Yes, sometimes $(n, \%)$ & $96(41.0 \%)$ & $42(43.3 \%)$ & 78 (88.6\%) & $216(51.6 \%)$ \\
\hline No $(n, \%)$ & $28(12.0 \%)$ & 17 (17.5\%) & $5(5.7 \%)$ & 50 (11.9\%) \\
\hline Missing data $(n, \%)$ & $14(6.0 \%)$ & $16(16.5 \%)$ & $2(2.3 \%)$ & $32(14.6 \%)$ \\
\hline
\end{tabular}


valued by health care professionals; ITP is valuable; ITP lacks clarity; and the value of ITP is not shared/recognised more widely.

Although only a third of our respondents identified themselves as currently offering ITP, 73.4\% of respondents reported wanting to do more $(67.1 \%$ of nurse respondents, $73.9 \%$ of pharmacists and $89.7 \%$ of GPs. Most participants felt ITP was a legitimate part of their professional role $(68.9 \%$ of all respondents; $93.8 \%$ of GPs, $69.3 \%$ of pharmacists and $60.2 \%$ of nurse prescribers). ITP is seen as an integral part of wider professional practice with $356(85.0 \%)$ participants reporting that their colleagues were doing ITP all or some of the time. These data indicating the valued and valuable nature of ITP were supported by the free text responses (Table 3, with further detail given in Table 4).

However, some uncertainties were expressed by professionals about the value and purpose of ITP. For example, one GP valued individual tailoring "so long as the patient doesn't miss out". Inconsistencies in responses suggested that some had understood our description of
ITP in a different sense than we had intended. We understand ITP to support the potential need for compromise between the preferences and priorities of guideline 'best practice' and patient perspectives. Yet we identified examples of practitioners describing that they always work within guidelines, whilst also reporting that they were delivering Individually Tailored Care. Findings also suggested a possible gap between what professionals value/want to do, and how they actually practice. A view echoed in this response from a GP who described:

"I suspect I tailor medicines much less than I would like to think I do" (GP)

Professionals commonly reported that they thought their organisation didn't recognise ITP as a legitimate role for them, although GPs were more likely to feel this role was accepted $33.1 \%$ of Nurse Prescribers and pharmacists compared with $52.6 \%$ of GPs stated that ITP was seen as a legitimate role by their employers). Given the high percentage of participants reporting doing ITC

Table 3 Summarising themes from qualitative analysis

\begin{tabular}{|c|c|c|}
\hline \multirow[t]{5}{*}{ Sense making } & Theme & Description \\
\hline & ITP valued by health care professionals & Meeting needs of the individual part of professional identity \\
\hline & ITP valuable to NHS & Professionals recognised the value of ITP to the NHS \\
\hline & Clarity on ITP & Prioritising the patient/person as the essence of ITP \\
\hline & Value of ITP not shared & $\begin{array}{l}\text { Organisation values and processes don't support ITP; some } \\
\text { patients don't understand value of ITP }\end{array}$ \\
\hline \multirow[t]{5}{*}{ Engagement } & Theme & Description \\
\hline & Leadership (individual and collective) & Key individual leaders, and collective engagement with ITP \\
\hline & Levels of engagement & Variable levels of engagement, with desire for more \\
\hline & Patient engagement & Mobilisation of patient engagement through the media \\
\hline & Barriers to engagement & $\begin{array}{l}\text { Included workload, fragmentation of services, fear, patient } \\
\text { resistance }\end{array}$ \\
\hline \multirow[t]{7}{*}{ Action } & Theme & Description \\
\hline & Formal training & In generalist practice; within specialist \\
\hline & Experiential learning - phronesis & $\begin{array}{l}\text { Learning from experience, including working with patients } \\
\text { and colleagues }\end{array}$ \\
\hline & Collective action & Value of peer discussion \\
\hline & Other supports for action & Including the media \\
\hline & Partial action & Easier to tailor stopping medicines than starting them \\
\hline & Barriers & Governance (fear), time, 'head space' and practical support \\
\hline \multirow[t]{5}{*}{ Monitoring } & Theme & Description \\
\hline & Mixed feedback & Both supportive and negative feedback on ITP \\
\hline & Challenge of feeding back & Hard to quantify benefit \\
\hline & Challenging the status quo & Hard to 'go against' the guideline \\
\hline & Potential power of feedback & Should be a Key Performance Indicator \\
\hline
\end{tabular}


Table 4 Detailed account of themes from qualitative analysis. Provides a more detailed description of the qualitative data as summarised in Table 3

\begin{tabular}{|c|c|c|}
\hline \multirow[t]{2}{*}{ Sense making } & Theme & Subtheme \\
\hline & ITP valued by health care professional & Defines professional role \\
\hline & \multirow[t]{2}{*}{ ITP valuable to NHS } & False economy not to \\
\hline & & But uncertain \\
\hline & Clarity on ITP & Prioritising the patient \\
\hline & \multirow[t]{3}{*}{ Value of ITP not shared } & By patients \\
\hline & & By organisational values \\
\hline & & By organisational structures \\
\hline \multirow[t]{2}{*}{ Engagement } & Theme & Subtheme \\
\hline & Leadership & Individuals \\
\hline
\end{tabular}

Collective action

Levels of engagement

$\begin{array}{ll} & \text { Desire for more } \\ \text { Patient engagement } & \text { Media } \\ \text { Barriers to engagements } & \text { Excess workload }\end{array}$

Fragmentation of care; lack of integration of vision and process

Fear

Patient resistance
Descriptions from participants

"our job starts where the guideline ends" (GP) And not just in managing medicines (Nurse Prescriber)

"could improve care and save money" (GP) "Needs to be developed" (Pharmacist)

"so long as patient don't miss out" (GP)

"advising on the suitability for the patient" (Pharmacist)

Principle of personalised medicine

"pts... need to understand prescribing as important as prescribing" (Pharmacist)

"recognition from the powers that be that this is a good thing to do" (GP)

"would be difficult to instigate in practice due to protocol driven practice" (Nurse Prescriber) "needs recognition that this is clever subtle stuff that needs skilled practitioners...not readily done by rote" (GP)

\section{Descriptions}

Key leaders, influential colleagues, trained colleagues support engagement. "working through examples with trusted colleagues" (pharmacist)

"I remember a Protected Learning Time session where a geriatrician talked about the rationale for stopping nearly all the medication" (GP) Independent contractual status for GPs supports engagement

Multidisciplinary team working enhances engagement with ITP

Engage with idea if not the practice (GP) Pharmacists role to recognise the potential need even if don't do ourselves

"want to do more discontinuation of meds" (Nurse Prescriber)

Media input in to dangers and harms of medicines can help as it starts a conversation

"limited by time, caseload and so lack of mental capacity" (GP).

Time and complexity mitigate against depth of conversation needed. Stopping meds increases workload - follow up consults

Inefficiency crowding out effort; disparity between primary and secondary perspectives, power and resources; population over individual focus

Limits engagement "it's a fear of making a mistake and the potential consequences" (GP)

Patients can be reluctant to change "can be difficult to persuade carers and patients to change meds they've been taking for a long time and were told were for life" (Pharmacist)

Patient expectations and lack of understanding of greyness of medicines

\section{Descriptions}

Generalist training; basic principles; knowing the guidelines before you deviate off

"this wasn't taught when I was training" (GP) 
Table 4 Detailed account of themes from qualitative analysis. Provides a more detailed description of the qualitative data as summarised in Table 3 (Continued)

\begin{tabular}{|c|c|c|}
\hline & Specialist training & $\begin{array}{l}\text { Prescribing (stop-start); working within specialist } \\
\text { area easier to do ITC }\end{array}$ \\
\hline \multirow[t]{3}{*}{ Experiential learning-phronesis } & Self taught/experience & $\begin{array}{l}\text { "experience gained intuition"; (GP) practiced at } \\
\text { doing this over a long time }\end{array}$ \\
\hline & Learn from patients & "just day-to-day learning from patients" (GP) \\
\hline & Learn from colleagues & $\begin{array}{l}\text { Trusted colleagues and influential figures; shared } \\
\text { reflection including on line discussion }\end{array}$ \\
\hline Collective action & Peer discussion & $\begin{array}{l}\text { MDT and collaborative action supports ITP } \\
\text { (but can inhibit decision making too as need } \\
\text { full agreement). Supervision }\end{array}$ \\
\hline Other support & Media & To start the conversation \\
\hline Partial action & & Easier when stopping meds than starting \\
\hline \multirow[t]{6}{*}{ Barriers } & Organisational practice - pay for performance & $\begin{array}{l}\text { Lack of joined up thinking and communication; } \\
\text { monitoring as a barrier }\end{array}$ \\
\hline & Time & \\
\hline & Resource & $\begin{array}{l}\text { Qualified and experience staff lacking; resource } \\
\text { prioritises opposite approach; imbalance need } \\
\text { and supply; peer senior support and continuity } \\
\text { of same needed; legal support } \\
\text { "resource restriction means prioritise safety and } \\
\text { supply" (Pharmacist) }\end{array}$ \\
\hline & Mental capacity and complexity & $\begin{array}{l}\text { "Limited by time caseload and so lack of mental } \\
\text { capacity" (GP); exhaustion } \\
\text { "To operate outside 'recognised prescribing' } \\
\text { requires understanding of the clinical evidence } \\
\text { supporting the current guidelines, when there } \\
\text { are gaps in that evidence and when it is therefore } \\
\text { appropriate to choose a different path. An } \\
\text { important variable is the patient wishes and how } \\
\text { these should be accommodated" (Pharmacist) }\end{array}$ \\
\hline & Practical advice & Practical advice, a framework, training \\
\hline & Fear & $\begin{array}{l}\text { Making and recording defendable decisions; being } \\
\text { castigated by others - clinicians, legally, morally; } \\
\text { uncertainty re risk } \\
\text { "Shared balanced discussions with patients rarely } \\
\text { results in a DEFENDABLE decision. If you are way } \\
\text { of the mark with clinical decisions then it is } \\
\text { probably sensible to share your decision with } \\
\text { colleagues" (GP) } \\
\text { "Fear of being misunderstood \& misinterpreted as } \\
\text { undertreatment, apathy, fear of going against } \\
\text { guidelines \& being medicolegally vulnerable" (GP) }\end{array}$ \\
\hline Theme & Subtheme & Discussion \\
\hline \multirow[t]{2}{*}{ Mixed feedback } & Positive & $\begin{array}{l}\text { From patients and colleagues helps confidence, } \\
\text { helps staff to prescribe less not more - more } \\
\text { PCC "each time I see a positive effect am } \\
\text { motivated to do more" (Nurse Prescriber) }\end{array}$ \\
\hline & Negative & $\begin{array}{l}\text { From colleagues (secondary care) and patients } \\
\text { (complaints) } \\
\text { "I stopped metformin in a 90-year-old with dementia, } \\
\text { daughter complained, made me wary to deprescribe" } \\
\text { (GP) }\end{array}$ \\
\hline Challenge of feeding back & Demonstrating impact & Hard to quantify benefits (GP) \\
\hline \multirow[t]{2}{*}{ Challenging the status quo } & Fear of feedback & $\begin{array}{l}\text { "If there is a problem may be hard if against the } \\
\text { guideline" (GP) }\end{array}$ \\
\hline & Monitoring as a barrier & $\begin{array}{l}\text { Accept only small deviation, monitoring from } \\
\text { population not individual perspective, pressure } \\
\text { to prescribe to QOF. } \\
\text { "should be a KPI" [KPI = Key Performance indicator] }\end{array}$ \\
\hline Potential power of feedback & & Should be a KPI \\
\hline
\end{tabular}


at least some of the time, these data suggest that ITP is an aspect of practice that may be happening 'under the radar'. Free text comments echoed these responses with reported lack of support from both non-front line staff, the organisational systems (including quality structures and pay for performance) designed to drive care, and patients.

"[ITC needs] recognition from the powers that be that this is a good thing" (GP)

"patients need to understand not prescribing as important as prescribing" (Pharmacist)

In summary, survey findings revealed that, in principle, ITP is recognised as an integral (valued and valuable) part of professional practice but its lacks a clear and consistent account of what it is and why it matters. Furthermore, its value is not perceived to be recognised by the wider healthcare community.

\section{Engagement}

NPT states that for ITP to be integrated into usual care, key individuals must lead the work whilst others must be willing to both get involved and then stay involved in this form of work - including operationalising the tasks in the context of frontline care [17].

As previously stated, some people described themselves as doing ITP; more wished to be more involved. Free text responses offer insights into perceived enablers and barriers to engagement, with four themes identified (Tables 3 and 4): leadership, levels of engagement, patient engagement and barriers to engagement.

Leadership for this work comes from individuals, but is also supported by collective action in the form of multidisciplinary team working (Table 4). Different levels of engagement were evident. Some professionals supported the idea in principle but did not see it as part of their own role to deliver this form of care. Others wanted to engage more with at least some aspects of practice, for example the discontinuation of medicines in vulnerable people. Patient support for this form of practice was acknowledged as an important enabler for professional engagement. Factors external to the health service, including the media, were recognised as key to mobilising patient support.

"it can be difficult to persuade patients and carers to change medicines they've been using for a long time" (Pharmacist)

Key emerging barriers to engagement related to the practical constraints of workload placing limits on the necessary time and 'head space' needed to engage with this complex form of clinical practice.

$$
\begin{aligned}
& \text { "limited by time, caseload and so lack of mental } \\
& \text { capacity" (GP) }
\end{aligned}
$$

"I barely get through the day reacting" (GP)

The survey findings again indicate a variable response in this second domain of work described by NPT. Results highlighted professionals both leading and engaging with work to deliver ITP, but also demonstrated significant barriers to engagement, notably in prioritising this work within a busy wider schedule of service delivery. The importance of engaging patients, as a key resource to support this activity, was highlighted.

\section{Action}

The third domain of work described by NPT focuses on action - that the people tasked with delivering ITP are able to do the tasks required of them. This includes the need for specific activities of work to be allocated to those with the right skills to do them, the provision of necessary resources by the host organisation, and that people then do the work [17]. Again, the data reveal a varied picture within five key themes: formal training, experiential learning, collective action, partial action and barriers to action (Tables 3 and 4).

Respondents were asked to indicate if they had ever had formal or informal training in the skills needed to tailor prescribing to individual needs. Table 5 summarises the results which showed low levels of formal training in this form of practice with high proportions of respondents across all professional groups expressing a desire for more training.

However, people described having informally acquired skills, described as "experience gained intuition" gathered through "practice...over a long time" (Table 4). Practitioners identified both patients and colleagues as important sources of support for this form of practice more so than formal training or professional status (Table 5). Free text responses revealed the significance of collective action (multidisciplinary working and discussions) in supporting this complex form of practice (Tables 3 and 4). The importance of peer discussion to support this form of practice was highlighted. This was accessed through a number of routes, including multidisciplinary team meetings, learning from trusted colleagues and influential figures, and the value of peer discussion including on-line discussion groups.

We observed professional differences within reported levels of confidence in different aspects of the role of ITP (Table 5), reflecting the level of prescribing-related training and experience within each group. Pharmacists 
Table 5 Reported skills, training and support for ITP across professional groups

\begin{tabular}{|c|c|c|c|c|}
\hline & Nurse prescribers $(n=234)$ & Pharmacists $(n=88)$ & $\mathrm{GP}(n=97)$ & Total $(n=419)$ \\
\hline \multicolumn{5}{|c|}{ Numbers (\%) reporting medium or high levels of practice skills in... } \\
\hline Assessing patient management of medicines & $153(65.4)$ & $66(75)$ & $75(77.3)$ & $309(73.7)$ \\
\hline Eliciting patient goals & $119(50.1)$ & $48(54.5)$ & $57(58.8)$ & $237(56.6)$ \\
\hline Deciding medicines meds to change & $111(47.4)$ & $55(62.5)$ & $72(74.2)$ & $250(59.7)$ \\
\hline Monitoring impact of change & $122(52.1)$ & $39(44.3)$ & $50(51.5)$ & $226(53.9)$ \\
\hline \multicolumn{5}{|l|}{ Described support from [n(\%)] } \\
\hline My training & $114(48.7)$ & $47(53.4)$ & $43(44.3)$ & $219(52.3)$ \\
\hline My professional status & $80(34.2)$ & $38(43.2)$ & $48(49.5)$ & $176(42.0)$ \\
\hline My colleagues & $131(60.0)$ & $57(64.8)$ & $61(62.9)$ & $264(63.0)$ \\
\hline My patients & $130(55.6)$ & $53(60.2)$ & $73(75.3)$ & $272(65.0)$ \\
\hline \multicolumn{5}{|l|}{ Expressed training experience/needs [n(\%)] } \\
\hline Had formal training & $39(16.7)$ & $16(18.2)$ & $12(12.4)$ & $74(17.7)$ \\
\hline Had informal training & $81(34.6)$ & $37(42.0)$ & $51(52.6)$ & $178(42.5)$ \\
\hline Would like more training & $129(55.1)$ & $59(67.0)$ & $67(69.1)$ & $267(63.7)$ \\
\hline
\end{tabular}

and GPs were generally (although not consistently) more confident in deciding on medicines to change. Nurses and GPs were more comfortable with monitoring the impact of changes - perhaps reflecting their continuing clinical contact with the patients. Overall, there was greater expressed confidence in aspects of prescribing practice that also form part of the usual practice of medicines management namely assessing patients' own management of their medicines. A relatively low proportion of respondents expressed confidence in eliciting patient goals for their medication, a finding supported by the existing literature.

Consistent with this mixed picture with reference to training and experience, participants also described 'partial action' - an incomplete tailoring of prescribing. For example, they described finding it easier to stop medicines than to think differently about starting them. They called for more practical resources to help them translate an ideal of practice into reality on the ground (training, a framework of practice, practical advice).

"This was not taught when I trained. A guide to implement this safely would be helpful" (GP)

Drawing on past research, we asked participants to describe whether they had experienced previously described [15] barriers to individual tailoring of care. Professionals report high levels of these known barriers (Table 6). Over half reported time as a significant barrier, $43.9 \%$ reported competing pressures and $40.5 \%$ reported making/recording a defendable decision as a key barrier to ITP. Interestingly about half of GPs compared with one third of nurse prescribers described this latter barrier. Potentially linked with this was concern about a lack of resources to support estimation of risk - see Table 4).

Organisational structures including performance monitoring were also consistently highlighted as a barrier to this way of working. Respondents described that they lacked the necessary resources from their host organisation to support this work, although with interprofessional differences in perceptions. Only 118 (50.4\%) of nurse prescribers and $45(51.1 \%)$ of pharmacists described having sufficient resources, whilst $72(74.2 \%)$ of GPs identified that that they did have sufficient resource. It is unclear whether this represents a true difference in the support offered to professional groups or an artefact of the research process with variable understanding of what the survey instrument meant by 'resource'.

Perhaps the most stark identified barrier was the theme of 'fear' - of being castigated by other professionals for not following guidelines, of the medicolegal implications of this way of working, and a lack of confidence in making and recording "defendable decisions".

Table 6 Number (\%) of respondents reporting previously identified barriers to ITP

\begin{tabular}{llllll}
\hline Barriers: & Time & Competing pressures & Risk stratification & Defend decision & Lack risk estimation support \\
\hline Nurse prescriber $(n=234)$ & $91(38.9)$ & $76(32.5)$ & $42(17.9)$ & $87(37.1)$ & $83(35.5)$ \\
Pharmacist $(n=88)$ & $48(54.5)$ & $45(51.1)$ & $31(35.2)$ & $38(43.2)$ & $39(44.3)$ \\
GP $(n=97)$ & $87(89.7)$ & $65(67)$ & $45(46.4)$ & $49(50.5)$ & $68(70.1)$ \\
All $(n=419)$ & $235(56.1)$ & $195(46.5)$ & $120(28.6)$ & $180(43.0)$ & $200(47.7)$ \\
\hline
\end{tabular}


"a fear of making a mistake and the potential consequences"(Nurse Prescriber)

"hard to record decision and be sure will be understood" (GP)

There was a call for additional qualified and experienced staff to support colleagues in this form of practice. The need for continuity of senior support, in terms of both clinical mentorship and medicolegal advice, was highlighted.

In summary, responses in the Action domain revealed the practical challenges in delivering a model of care that many supported in principle. Much of the existing training for this role was identified as experiential, including recognising the importance of peer support from colleagues. There was suggestion from some, but not all, that formal GP training may support this way of working. The recurring theme of lack of time and energy once more appeared strongly - of exhausted staff being unable to perform this highest-level clinical function. The other key identified barrier was fear - of not being supported in this form of decision making by other health professionals, by the 'system' and perhaps by patients too. This is an issue that feeds in to our final NPT domain.

\section{Monitoring}

NTP states that for ITP to be integrated into usual practice, stakeholders must get feedback about the effect of the intervention; individuals and the collective must assess the feedback as being supportive of the tasks of ITP; and feedback must support ongoing learning and development [17]. Analysis in this domain again revealed significant concerns/barriers to integration.

In an era of evidence-based, or evidence-informed, medicine, we asked our participants if they were aware of any evidence supporting ITP. Fifty-five respondents (13.1\%) said yes; 290 (69.2\%) said no.

Only one in four (26.3\%) participants described having received feedback on their ITP, and of these, $37.2 \%$ describing that feedback had changed their practice. There was no difference identified between professional groups. Free text responses revealed four themes (Tables 3 and 4): mixed feedback, challenges of feeding back, challenging the status quo, and potential power of feedback.

Feedback had a mixed effect on practice. Positive feedback helped build confidence, encouraging staff to "prescribe less not more" and in a more "patientcentred" approach. One Nurse Prescriber described "each time I see a positive effect, I am motivated to do more". However, others spoke of how complaints from both colleagues (in secondary care) and carers made them warier:
"I stopped metformin in a 90-year-old with dementia, daughter complained, made me wary to deprescribe" (GP)

Others also reported current feedback mechanisms (performance monitoring) as a significant barrier - the "pressure to prescribe to QOF" (GP) with only "small deviations" permitted.

Participants reflected on the challenges of demonstrating the impact of individually tailored care beyond the effect on an individual patient - in recognising potential benefits.

"will be difficult to quantify downstream costs [that] will be saved - mainly by those outside of my practice so i will do work and savings will be made elsewhere" (GP)

But recognised the potential power of feedback as a source of support for practice commenting that individually tailored prescribing should be a "key performance indicator" (GP).

In summary, responses revealed that current feedback-whether formal or informal - is largely nonsupportive or even unsupportive of ITC. Performance monitoring therefore functions as a further barrier to changing to an individually tailored model of prescribing. Respondents revealed that positive/reinforcing feedback comes mainly from patients as well as discussion with colleagues - through informal sources.

\section{Discussion}

\section{Summary}

Our findings revealed general support for a principle of ITP but significant variation and inconsistency in understanding and implementation of practice. Key themes emerging from our analysis describe 3 enablers and 4 barriers for ITP (Table 7). ITP is recognised as an integral part of professional practice but with a lack of clarity in describing what it is which limits wider engagement and understanding. ITP is not prioritised within current models and organisation of care. Delivery of ITP is supported by experiential and peer learning but professionals identify a need for more help in developing the practical skills to support Defendable Decision Making. Professionals highlight the importance of being able to follow up patients in order to monitor the impact of decision making, but also the need to review the impact of formal performance monitoring as a barrier to ITP. From these findings, we describe four key implications for practice: the need to raise understanding of ITP as a legitimate part of professional practice; to prioritise the work of ITP within the range of individual professional activity; to improve the consistency of training and support for interpretive practice; and to review the impact of formal and informal monitoring processes on practice. 


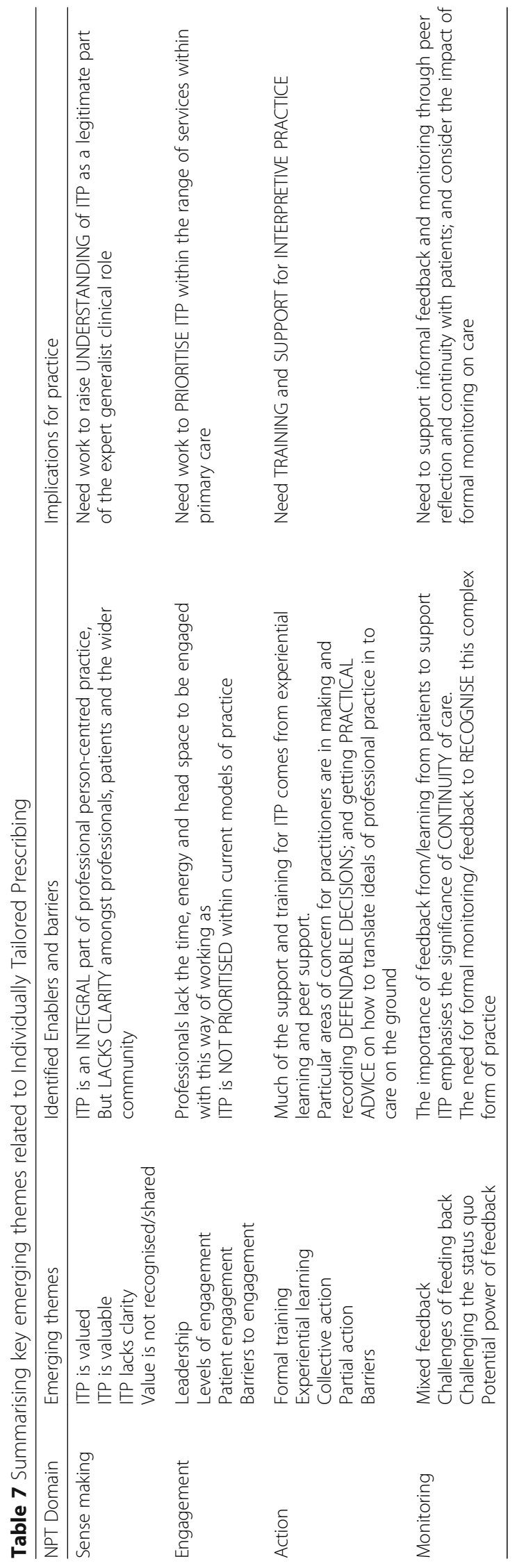




\section{Comparison with existing literature}

The identified barriers resonate with, and extend, the findings of our previous survey on barriers to generalist practice [15]. The current survey recognises that clarity of understanding, prioritisation of work, training and feedback remain issues that need to be addressed in the new model of care. However, the survey adds to previous findings by highlighting the importance of patient understanding of the model of care as a potential enabler and barrier. Patient support was identified as a key driver for ITP by respondents; fear of patient dissent or complaint as a barrier. This survey extends the previous findings in noting the potential for multiprofessional groups in supporting engagement with, and so delivery of this model of practice. Although all professional groups recognised the need for more training, pharmacists in particular were identified as an underdeveloped resource. The importance of medicolegal training and support was a strong theme, and resonates with informal discussions on this topic that we have held with professional stakeholder groups. The revised PRIME Prescribing model will recognise the need for medicolegal training in its training programme. Finally, the results highlight the importance of shared reflection and monitoring and of peer professional support, an extension of our previous survey [15]. This observation also resonates with the wider literature on professional practice. Gabbay and Le May describe the importance of peer reflection in supporting complex, beyond guideline practice [19].

Our survey also resonates and extends observations from previous qualitative work. Both Denford and colleagues [2] and Sinnott [20] highlight professional variation in understanding of the process of ITP but also recognise the significance of a process of compromise. Our survey extends those observations to a larger sample, and across professional boundaries. Barriers of time and resource to engagement with ITP have been previously described [586 but our findings go further in emphasising the importance of 'head space'. The need is not simply for more time, but for protected time that recognises the significant intellectual challenges of this work. Practitioners may not just need more time, but fewer other demands/activities to leave them with sufficient mental capacity for the work involved.

The RCGP recognises GPs as expert generalists [21]. Our survey findings suggest that many are working in that role - able to individually tailor care to the needs of a whole person, the individual. However, participants also report a significant gap in their training - a lack of formal training to deliver these tasks. Indeed, many report training being acquired through experience and learning from significant others. This requires us to have a workforce able to act in that mentor role, and with people working in roles and rotas that allow them access to that apprenticeship. The findings highlight a need to look again at the RCGP training curriculum to both strengthen formal training and protect the informal.

Concerns about the impact of current performance monitoring on individually tailored practice have been previously recognised [20]. Our survey offers new data in highlighting professional suggestions that monitoring could be explicitly used to encourage this model of care [21].

\section{Strengths and limitations of our work}

Our work describes theory informed research, underpinned by the principles described in the MRC Complex Interventions Framework [22] to develop a new complex intervention. Support for our emerging model comes from the observation that our findings resonate with previous research and with the experiences of clinical audiences we have shared the findings with. This report offers a transparent description of development of an intervention supported by literature and empirical findings.

However, we recognise a number of ongoing limitations with the work. This survey focused only on professional perceptions. We have public and patient partners actively working with us on the development of all stages of this work [23], and we have actively prioritised literature on patient experiences of medicines use in designing our work [24]. However, we still need to more formally examine the views of patients who have been unconnected with the work to date.

The mixed responses reveal some lack of clarity/understanding of what we meant by ITP in our survey which requires us to exercise caution in interpreting and extrapolating our findings. We deliberately chose not to fully describe the proposed PRIME Prescribing model in our survey so as to allow people to comment on their own current practice. But our work may now benefit from repeating the study with a clearer description of the specific intervention that we are proposing in the participant information.

Our snowball sample was never intended to be fully representative. Our research methodology is based on a translational approach - action research involving clinicians and academics working together to develop implement and evaluate new models of working [25]. As such the current model is evidence and stakeholder informed, but subject to ongoing review through implementation and formative evaluation.

\section{Implications for research and practice}

The findings from this study are being used to refine the description of our PRIME Prescribing intervention. Key additions include the inclusion of a section on medicolegal issues and patient safety within the educational component supporting interpretive practice [26] and clinical decision making. We will work with our patient partners 
to describe practical support for clinicians in engaging their patients in a change to ITP, and facilitate proactive peer reflection and support to enhance the critical professional learning needed to support 'beyond protocol' care [19]. We will actively work with stakeholders to consider how we might include a key performance indicator based on fidelity of delivery of a process of individually tailored care. Finally, we will be actively working to raise the profile and understanding of ITP amongst patient and non-clinical groups (for example, service managers).

\section{Conclusion}

The 2013 Kings Fund report argued that to optimise the potential benefit of polypharmacy on patient-centred outcomes, we must find ways to support compromise between the views of clinicians and patients when making decisions about medicines use [1]. Our survey findings highlight that such work is already happening, but inconsistently and with insufficient support. We have described professional perceptions of changes needed to enhance the individually tailored use of medicines. We now propose to test the findings of this study through incorporating them into the refined description of the complex intervention that is PRIME Prescribing, and so evaluate the impact of introducing these changes to practice.

\section{Additional file}

Additional file 1: FLIPMEDS: the survey tool. Details the survey tool used in the study. (DOCX $20 \mathrm{~kb}$ )

\section{Abbreviations}

EGP: Expert Generalist Practice; ITP: Individually Tailored Prescribing; MRC: Medical Research Council; NPT: Normalisation Process Theory; RCGP: Royal College of General Practitioners; SAPC: Society for Academic Primary Care

\section{Acknowledgements}

The authors thank our patient partners for their ongoing support of the FLIPMEDS work and for their comments on early drafts of the proposal for this work - Ed Ranson, Jim Harris, and Michelle Dickenson. We also thank all the anonymous participants who completed the survey.

\section{Funding}

The current work is unfunded.

\section{Availability of data and materials}

The datasets used and/or analysed during the current study available from the corresponding author on reasonable request.

\section{Authors' contributions}

$J R, N B, R B, J H$, and JK participated in study design, data acquisition, analysis, interpretation, and preparation of the manuscript. JF participated in data analysis and manuscript preparation. JR is corresponding author and stands as guarantor for this work. All authors read and approved the final manuscript.

\section{Ethics approval and consent to participate}

Our study was performed in accordance with the principles described in the Declaration of Helsinki. Ethical approval for our study was granted by Warwick Medical School BSREC REGO-2016-1749). The survey instrument (Additional file 1) informed potential participants that completion was voluntary, responses were anonymous and people could leave the survey at any point without their data being saved. Continued participation constituted consent to use anonymised data in the further development of this work.

\section{Consent for publication}

Individual consent for publication is not required as no personally identifiable information was collected. The invitation to complete the study informed participants that analysis of their anonymised data would be written up in an academic journal. Continued participation in the survey was taken as implied consent as agreed within our Ethics approval.

\section{Competing interests}

The authors declare that they have no competing interests.

\section{Publisher's Note}

Springer Nature remains neutral with regard to jurisdictional claims in published maps and institutional affiliations.

\section{Author details}

${ }^{1}$ Hull York Medical School, Hull University, Cottingham Road, HU67RX, Hull, England. 'University of Exeter Medical School, St Luke's Campus, Heavitree Road, EX1 2LU Exeter, England. ${ }^{3}$ Clinical Trials and Health Research, Peninsula Schools of Medicine and Dentistry, ITTC, Drake Circus, PL4 8AA Plymouth, England. ${ }^{4}$ Warwick Primary Care, Warwick Medical School, University of Warwick, CV4 7AL Coventry, England. ${ }^{5}$ Division of Health Research, University of the Highlands and Islands, 10 Inverness Campus, IV2 5NA Inverness, Scotland. ${ }^{6}$ Medway School of Pharmacy, The Universities of Greenwich and Kent at Medway, Anson Building, Central Avenue, Chatham Maritime, Chatham Kent ME4 4TB, Canada.

Received: 21 March 2017 Accepted: 26 December 2017

Published online: 15 January 2018

\section{References}

1. Duerden M, Avery T, Payne R. Polypharmacy and medicines optimisation. Making it safe, making it sound. Kings Fund. 2013. https://www.kingsfund. org.uk/publications/polypharmacy-and-medicines-optimisation. Accessed 1 Jan 2018.

2. Denford, Frost, Dieppe, Cooper, Britten. Individualisation of drug treatments for patients with long-term conditions: a review of concepts. BMJ Open 2014;4: e004172.

3. Stehlik J, Taylor D. And an ARB makes nine: polypharmacy in patients with heart failure. Cleve Clin J Med. 2004;71:674-6.

4. Aronson KR. Polypharmacy - appropriate and inappropriate. $\mathrm{Br} J$ Gen Pract. 2006:56:484-5

5. Krska J, Katusiime B, Corlett SA. Validation of an instrument to measure patient experiences of medicines use: the living with medicines questionnaire (LMQ). Patient Prefer Adherence. 2017;11:671-279.

6. Reeve J, Cooper L. Rethinking how we understand individual health care needs for people living with long term conditions: a qualitative study. Health and Soc Care Community. 2016;24:27-38.

7. Gallacher K, May CR, Monitori VM, Mair FS. Understanding patient experiences of treatment burden in chronic heart failure using normalisation process theory. Ann Fam Med. 2011;9:235-43.

8. Mair FS. Thinking about the burden of treatment. BMJ. 2014;349:g6680.

9. Demain S, Gonçalves A-C, Areia C, Oliveira R, Marcos J, Marques A, Parmar R, Hunt K. Living with, managing and minimising treatment burden in long term conditions: a systematic review of qualitative research. PLoS One. 2015; https://doi.org/10.1371/journal.pone.0125457.

10. Milton JC, Jackson SH. 2007. Inappropriate polypharmacy, reducing the burden of multiple medication. Clin Med. 2007;7:514-7.

11. Mohammed MA, Mdes RJ, Chen TF. Medication-related burden and pateints' lived experience with medicines: a systematic review and metasynthesis of qualitative studies. BMJ Open. 2016; https://doi.org/10. 1136/bmjopen-2015-010035.

12. Pound, Britten, Morgan, Yardley, Pope et al Resisting medicines: a synthesis of qualitative studies of medicine taking. Soc Sci Med 2005;61:133-155.

13. Townsend A, Wyke S, Hunt K. Self-managing and managing self: practical and moral dilemmas in accounts of living with chronic illness. Chronic IIIn. 2006;2:185-94. 
14. Lindsay S. Prioritizing illness: lessons in self-managing multiple chronic diseases. Can J Sociol. 2009;34:983-1002.

15. Reeve J, Dowrick C, Freeman G, Gunn J, Mair F, May C, Mercer S, Palmer V, Howe A, Irving G, Shiner A, Watson J. Examining the practice of generalist expertise: a qualitative study identifying constraints and solutions. JRSM Short Rep. 2013; https://doi.org/10.1177/2042533313510155.

16. Fleming J, Patel P, Tristram S, Reeve J. The fall and rise of generalism: perceptions of generalist practice amongst medical students (Letter). Education for Primary Care. 2017;28(4)

17. Normalisation Process Theory. http://www.normalizationprocess.org/. Accessed 1 Jan 2018

18. NoMAD Study. http://www.normalizationprocess.org/nomad-study/. Accessed 1 Jan 2018.

19. Gabbay J, le May A. Practice based evidence for healthcare: clinical mindlines. New York: Routledge; 2011.

20. Sinnott C, Mercer SW, Payne RA, Duerden M, Bradley CP, Byrne M. Improving medication management in multimorbidity: development of the MultimorbiditY COllaborative Medication Review And Decision making (MY COMRADE)intervention using the Behaviour Change Wheel. Implement Sci. 2015; https://doi.org/10.1186/s13012-015-0322-1.

21. Royal College of General Practitioners. Medical generalism: why expertise in whole person medicine matters. (2011) http://www.rcgp.org.uk/policy/rcgppolicy-areas/medical-generalism.aspx. Accessed 1 Jan 2018.

22. Medical Research Council. Developing and implementing complex interventions (2008) https://www.mrc.ac.uk/documents/pdf/complexinterventions-guidance/. Accessed 1 Jan 2018.

23. Reeve J, Dickenson M, Harris J, Ranson E, Donhnhammar U, Cooper L, Krska J, Byng R, Britten N. Solutions to problematic polypharmacy: learning from the expertise of patients. Br J Gen Pract. 2015;65:319-20.

24. Heaton J, Britten N, Krska J, Reeve J. Person-centred medicines optimisation policy in England: an agenda for research on polypharmacy. Prim Health Care Res Development. 2016; https://doi.org/10.1017/S1463423616000207.

25. Reeve J, Cooper L, Harrington S, Rosbottom P, Watkins J. Developing, delivering and evaluating primary mental health care: the co-production of a new complex intervention. BMC Health Serv Res. 2016;16:470.

26. Reeve J. Supporting expert generalist practice: the SAGE consultation model. Br J Gen Pract. 2015;35:207-8.

\section{Submit your next manuscript to BioMed Central and we will help you at every step:}

- We accept pre-submission inquiries

- Our selector tool helps you to find the most relevant journal

- We provide round the clock customer support

- Convenient online submission

- Thorough peer review

- Inclusion in PubMed and all major indexing services

- Maximum visibility for your research

Submit your manuscript at www.biomedcentral.com/submit 